\title{
Impact of New Solar Radiation Parameterization in the Eta Model on the Simulation of Summer Climate over South America
}

\author{
T. A. Tarasova, J. P. R. Fernandez, I. A. Pisnichenko, J. A. Marengo, J. C. Ceballos, and \\ M. J. BotTINO \\ Centro de Previsão de Tempo e Estudos Climáticos/Instituto Nacional de Pesquisas Espaciais, Cachoeira Paulista, São Paolo, Brazil
}

(Manuscript received 11 January 2005, in final form 8 August 2005)

\begin{abstract}
The regional Eta workstation (WS) model with horizontal resolution of $40 \mathrm{~km}$ has been integrated over South America for January 2003. The NCEP-DOE Reanalysis II was used for initial and lateral boundary conditions. The comparison of the model-simulated and satellite-derived values of monthly mean incident solar radiation at the surface demonstrates that the former values are larger by $20 \%-30 \%$ over the entire region. To improve the surface flux representation in the model, a new solar radiation scheme has been implemented in it. An offline comparison of the original and the new radiation schemes with the detailed line-by-line method demonstrates a higher accuracy for the new scheme. With the new scheme, the modelsimulated incident solar radiation at the surface is in a better agreement with the satellite-derived data. Nevertheless, a noticeable systematic difference of $10 \%-20 \%$ still remains, probably because of the incorrect description of cloud parameters in the model. The lower incident solar radiation in the new version of the model causes a decrease of near-surface air temperature by $0.1^{\circ}-1^{\circ} \mathrm{C}$ and a decrease of precipitation rate by up to $20 \%-30 \%$ over most of the continent. The increase in the simulated incident solar radiation and temperature is found in the region of the South Atlantic convergence zone, which is responsible for the enhanced cloudiness and precipitation in the central and southeastern parts of Brazil during summer. The model results are compared with observational data of meteorological stations, the Global Precipitation Climatology Project (GPCP), and the South American Low-Level Jet Experiment (SALLJEX) and are discussed.
\end{abstract}

\section{Introduction}

Regional weather forecast models are used in climate studies because of their high spatial resolution and inclusion of sophisticated parameterizations for physical processes. The improvement of model performances is partially related to refinements in the parameterizations of convection, cloudiness, radiation, and land surface processes. The accurate simulation of incident solar radiation at the earth's surface is a requirement for a better performance of all other parameterizations.

The regional Eta Model was originally developed at the National Centers for Environmental Prediction (NCEP; Mesinger et al. 1988; Janjic 1994; Black 1994) and is currently used at a few atmospheric research

Corresponding author address: Dr. T. A. Tarasova, CPTEC/ INPE, Rodovia Presidente Dutra, km. 40, 12630-000, Cachoeira Paulista, São Paulo, Brazil.

E-mail: tatiana@cptec.inpe.br centers, including Centro de Previsão de Tempo e Estudos Climáticos (CPTEC; the Brazilian Center of Weather Forecast and Climate Studies), for weather and climate modeling. A review on the simulation of the South American climate with the Eta Model is given by Chou et al. (2002). It is concluded that the model reproduces the main summer climate features reasonably well, among them is the formation of the South Atlantic convergence zone (SACZ) (Figueroa et al. 1995) and the low-level southward flow of the warm and moist air located to the east of the Andes (Saulo et al. 2000; Vernekar et al. 2003). The SACZ is mainly responsible for the cloudiness and precipitation in the central and southeastern Brazil. The flow determines summer precipitation in the south of Brazil, north of Argentina, and Uruguay. Nevertheless, the comparison of the model output with observational data demonstrates noticeable bias in precipitation rate and nearsurface air temperature in some regions of South America (Chou et al. 2000). Precipitation forecasts 
show lower accuracy at the tropical latitudes. The amount of precipitation tends to be overestimated in the case of low rainfall and underestimated in the case of high rainfall (Seluchi and Chou 2001). Also, the model has problems in forecasting near-surface air temperature.

The comparison of simulated solar radiative and other surface fluxes with observations shows that the Eta Model systematically overestimates incident solar radiation as well as latent and sensible heat fluxes at the surface (Hinkelman et al. 1999; Chou et al. 2002). To improve its surface fluxes representation, we implemented into the model a radiation scheme developed by Chou and Suarez (1999) and modified by Tarasova and Fomin (2000). This scheme includes the fine effects of gaseous absorption and particle scattering, which are not considered in the solar radiation code currently utilized in the Eta Model. Also, the new scheme uses a more accurate approach for a solution of the radiative transfer equation.

In this paper we analyze the impact of the new solar radiation scheme on surface fluxes and meteorological variables as simulated by the Eta workstation (WS) model over South America in summer. The month January 2003 has been selected for the analysis in order to estimate the impact of the new scheme on summer climate features such as strong convective precipitation and low-level transport of hot and humid air to the south. In section 2 , the original and the new solar radiation schemes are described and validated offline with the line-by-line (LBL) method. Section 3 gives short descriptions of the NCEP Eta Model and Eta WS model adopted for the integration. Modifications that we introduced in the model and its integration procedure are also described. Section 4 presents results of the study. Model-simulated and observed monthly mean fields of incident solar radiation, cloud cover fraction, near-surface air temperature, precipitation rate, and wind are compared. Time series and diurnal cycle of these variables averaged over selected regions are analyzed. Section 5 gives summary of the results and conclusion.

\section{Offline validation of the original and new solar radiation schemes}

The original solar radiation scheme SWR93 of the NCEP Eta Model follows the parameterizations of Lacis and Hansen (1974). The scheme accounts for the absorption lines of $\mathrm{H}_{2} \mathrm{O}, \mathrm{O}_{3}$, and $\mathrm{CO}_{2}$ as well as the reflection from the layers of molecular atmosphere and cloudiness. The solar radiation absorption by water vapor is computed with the broadband absorption function of Yamamoto (1962). The use of this function leads to underestimation of the atmospheric absorption, as demonstrated by detailed LBL calculations of Fomin and Gershanov (1996) using the high-resolution transmission molecular absorption database (HITRAN-96) spectroscopic database of Rothman et al. (1998). The SWR93 scheme also underestimates the atmospheric absorption because of the lack of the absorption by $\mathrm{O}_{2}$ and water vapor continuum.

We implemented into the Eta Model a new solar radiation scheme CLIRAD-SW-M developed at the National Aeronautics and Space Administration (NASA) Goddard Space Flight Center (GSFC) by Chou and Suarez (1999) and modified by Tarasova and Fomin (2000). The scheme CLIRAD-SW of Chou and Suarez (1999) is currently used in the atmospheric models developed at GSFC. This broadband code accounts in the parameterized form for the absorption lines of $\mathrm{H}_{2} \mathrm{O}, \mathrm{O}_{3}, \mathrm{O}_{2}$, and $\mathrm{CO}_{2}$, available in the HITRAN-96 database (Rothman et al. 1998), as well as for absorption and scattering properties of aerosol and cloud particles. The solar radiative transfer is calculated with the use of the delta-Eddington and two-stream adding approximations. The modified code CLIRAD-SW-M also takes into account the water vapor continuum absorption model proposed by Clough et al. (1989).

To estimate the scheme's accuracy, we performed the offline comparison of the SWR93 and CLIRAD-SW-M schemes with the LBL method of Fomin and Gershanov (1996). Radiative transfer calculations were performed for the test cases proposed by Fouquart et al. (1991). The LBL method accounts for the same absorption lines and water vapor continuum that are considered in the CLIRAD-SW-M scheme. Theoretically, however, the LBL method has a much higher accuracy because of its fine wavenumber grid of $1 / 256 \mathrm{~cm}^{-1}$ and use of the Monte Carlo technique in the radiative transfer calculations. The results of the comparison of the schemes are presented in Table 1 for the clear-sky test cases that take into account only gaseous absorption and molecular scattering. The difference between the SWR93 and LBL schemes varies from +20 to $+30 \mathrm{~W}$ $\mathrm{m}^{-2}$ for incident solar radiation and from -10 to -25 $\mathrm{W} \mathrm{m}{ }^{-2}$ for atmospheric absorption. This is largely related to the neglect of solar radiation absorption because of some water vapor lines, water vapor continuum, and $\mathrm{O}_{2}$ in the SWR93 scheme. The CLIRADSW-M scheme has a smaller deviation of $1-2 \mathrm{~W} \mathrm{~m}^{-2}$ for both incident solar radiation and atmospheric absorption when compared with the LBL method.

The CLIRAD-SW-M scheme also has a higher accuracy when used for radiative transfer calculations in a cloudy atmosphere. The cloud parameters used in the test cases 43 and 45 of Fouquart et al. (1991) are shown 
TABLE 1. Difference between clear-sky incident solar radiation at the surface $Q$ and atmospheric absorption $A$ as computed with the SWR93, CLIRAID-SW-M, and LBL schemes for test cases 31, 33,35 , and 37 , which include only gaseous absorption and molecular scattering; surface albedo is equal 0.2; MLS: midlatitude summer atmosphere; TRA: tropical atmosphere; SZA: solar zenith angle $\left({ }^{\circ}\right)$.

\begin{tabular}{cccccc}
\hline \hline & & & \multicolumn{3}{c}{$Q / A\left(\mathrm{~W} \mathrm{~m}^{-2}\right)$} \\
\cline { 3 - 6 } & & & $\begin{array}{c}\text { SWR93 }- \\
\text { LBL }\end{array}$ & $\begin{array}{c}\text { CLIRAD }- \\
\text { LBL }\end{array}$ & $\begin{array}{c}\text { CLIRAD - } \\
\text { SWR93 }\end{array}$ \\
\hline 31 & MLS & 30 & $+23 /-21$ & $0 / 0$ & $-23 /+21$ \\
33 & MLA & 75 & $+30 /-10$ & $0 / 0$ & $-30 /+10$ \\
35 & TRA & 30 & $+27 /-25$ & $+1 /-1$ & $-26 /+24$ \\
37 & TRA & 75 & $+33 /-2$ & $+1 /-2$ & $-33 /+10$ \\
\hline
\end{tabular}

in Table 2. Cases 43 and 45 describe an atmosphere with one cloud layer of the same optical depth of 2.8 . The top of the cloud layer is located at the altitude of 13 and $2 \mathrm{~km}$, respectively. Table 3 shows the difference in the incident solar radiation and atmospheric absorption values computed with the SWR93, CLIRAD-SW-M, and LBL schemes. The difference between the SWR93 and LBL schemes varies from 62 (case 43 ) to -79 (case 45) $\mathrm{W} \mathrm{m}^{-2}$. The change of the sign is related to the deficiency in the SWR93 scheme that calculates very different incident solar radiation for the high- and lowlevel clouds. Its magnitude changes from 835 to $697 \mathrm{~W}$ $\mathrm{m}^{-2}$, respectively. For the comparison, the LBL scheme provides the values of 773 and $776 \mathrm{~W} \mathrm{~m}^{-2}$ for these cases. The incident solar radiation values obtained from the calculations with the CLIRAD-SW-M and LBL methods differ by less than $8 \mathrm{~W} \mathrm{~m}^{-2}$ in both cases. Hence, the comparison of both schemes with the lineby-line method shows that the CLIRAD-SW-M scheme is much more accurate than the SWR93 scheme in both clear-sky and cloudy atmospheric conditions.

The offline comparison of the old and new solar radiation schemes is also needed to understand the difference in solar radiative fluxes obtained from the simulations with the two versions of the model. Tables 1 and 3 show that for the clear-sky and high-level cloudy cases the CLIRAD-SW-M scheme calculates smaller incident surface solar radiation and larger at-

TABLE 2. Cloud parameters used in test cases 43 and 45 for the radiation schemes intercomparison; cloud type, CT; cloud optical depth; COD; altitude of cloud top, $H$; effective radius of cloud particles, $R_{e}$; stratocumulus, CS.

\begin{tabular}{lcccc}
\hline \hline Case & CT & COD & $H(\mathrm{~km})$ & $R_{e}(\mu \mathrm{m})$ \\
\hline 43 & $\mathrm{CS}$ & 2.8 & 13 & 5.25 \\
45 & $\mathrm{CS}$ & 2.8 & 2 & 5.25 \\
\hline
\end{tabular}

TABLE 3. Difference between $Q$ and $A$, as computed with the SWR93, LBL, and CLIRAD-SW-M schemes for test cases 43 and 45 with clouds; surface albedo is 0.2 ; standard atmosphere is midlatitude summer (MLS); solar zenith angle is $30^{\circ}$.

\begin{tabular}{cccc}
\hline \hline & \multicolumn{3}{c}{$Q / A\left(\mathrm{~W} \mathrm{~m}^{-2}\right)$} \\
\cline { 2 - 4 } Case & SWR93 & CLIRAD - & CLIRAD - \\
& LBL & LBL & SWR93 \\
\hline 43 & $+62 /-10$ & $+6 /-5$ & $-56 /+5$ \\
45 & $-79 /+27$ & $+6 /-8$ & $+85 /-35$ \\
\hline
\end{tabular}

mospheric absorption than the SWR93 scheme. The reverse is in the case for the low-level cloudiness. When the continental aerosol model with a column optical depth of 0.2 (World Meteorological Organization 1986) is included in the calculations with the CLIRAD-SW-M scheme the difference between the CLIRAD-SW-M and SWR93 schemes varies from -60 to $-70 \mathrm{~W} \mathrm{~m}^{-2}$ for incident solar radiation and from +25 to $+50 \mathrm{~W}$ $\mathrm{m}^{-2}$ for atmospheric absorption (see Table 4). Thus, the Eta Model running with the new radiation scheme will provide smaller clear-sky incident solar radiation at the surface than that provided by the original Eta Model. In cloudy conditions, the incident solar surface radiation will be smaller or larger depending on the height of clouds.

\section{Model and experimental design}

We adopted for the integration of the Eta WS model of the University Corporation for Atmospheric Research (UCAR)/Cooperative Program for Operational Meteorology, Education and Training (COMET) (see information online at http://strc.comet.ucar.edu), which is almost identical to the operational NCEP Eta Model of 2003 but has more simplified installation, configuration, and running procedures. A short description of the NCEP Eta Model is given below as well as modifications that were introduced in the model and in the integration procedure.

TABLE 4. Difference in clear-sky $Q$ and $A$, as computed with the CLIRAD-SW-M and SWR93 schemes; the former scheme accounts for the continental aerosol model; surface albedo is 0.2 ; MLS: midlatitude summer atmosphere; TRA: tropical atmosphere; SZA: solar zenith angle.

\begin{tabular}{lccc}
\hline \hline ATM & SZA $\left(^{\circ}\right)$ & $Q\left(\mathrm{~W} \mathrm{~m}^{-2}\right)$ & $A\left(\mathrm{~W} \mathrm{~m}^{-2}\right)$ \\
\hline MLS & 30 & -65 & +52 \\
MLS & 75 & -66 & +25 \\
TRA & 30 & -67 & +54 \\
TRA & 75 & -68 & +25
\end{tabular}




\section{a. NCEP Eta Model short description}

The full description of the NCEP Eta regional forecasting model is given by Mesinger et al. (1988), Janjic (1994), and Black (1994). In short, the horizontal structure is described by a semistaggered $\mathrm{E}$ grid (Arakawa and Lamb 1977). The eta vertical coordinate is used to reduce numerical errors over mountains in computing the pressure gradient force (Mesinger et al. 1988). The planetary boundary layer processes are based on the Mellor-Yamada level-2.5 model (Mellor and Yamada 1974). The convective precipitation scheme that is of Janjic (1994), who modified the scheme of Betts and Miller (1986). The shortwave and longwave radiation parameterizations are those of Lacis and Hansen (1974) and Fels and Schwartzkopf (1975), respectively. The land surface scheme is that of Chen et al. (1997). A new grid-scale cloud scheme of Ferrier et al. (2002) has been recently incorporated in the NCEP Eta Model instead of the scheme of Zhao and Carr (1997). The grid-scale cloud cover fraction is parameterized as a function of the relative humidity and cloud water (ice) mixing ratio (Xu and Randall 1996; Hong et al. 1998). Convective cloud cover fraction is parameterized as a function of precipitation rate (Slingo 1987). The extinction coefficient for convective clouds is constant for two air temperature intervals. The grid-scale cloud extinction coefficient depends on cloud water (ice) mixing ratio, which is a prognostic variable of the model.

\section{b. Eta Model integration}

The Eta WS model has been installed in a supercomputer and modified to be able to perform climate runs. For this the restart subroutines have been rewritten. The restriction on the output file name was removed. The daily update of sea surface temperature from climatological data was incorporated. Then, the new radiation scheme CLIRAD-SW-M was implemented into the model, and clear-sky incident solar radiation at the surface was obtained as a new model output. The two versions of the model, with the original and new solar radiation schemes, were integrated over South America for January 2003. The integration was started on 0000 UTC 16 December 2002. The first 15 days were considered as the model spinup and excluded from the analysis. The NCEP-Department of Energy (DOE) Reanalysis-II data (T62/L28; Kanamitsu et al. 2002) were used for initial and lateral boundary conditions. The latter were updated every $6 \mathrm{~h}$. The sea surface temperatures were updated every day from the linearly interpolated monthly mean data of Reynolds et al. (2002), which are available as Global Ice and Sea Surface Temperature (GISST) data of the Hadley Centre of the Met Office. For the initial conditions of soil moisture its seasonal climatology was used. The model was integrated with horizontal resolution of $40 \mathrm{~km}$ and 38 levels in the vertical. The model domain covers South American continent and adjacent oceans $\left(40^{\circ} \mathrm{S}-12^{\circ} \mathrm{N}\right.$, $100^{\circ}-32^{\circ} \mathrm{W}$ ). The versions of the model, with original and new solar radiation schemes, are referred below as original and modified model versions, respectively.

\section{Results}

The results of the model simulations for January 2003 using two versions of the Eta Model with original and new solar radiation schemes are analyzed here in conjunction with available observational data. The analysis includes such variables as incident solar radiation, cloud cover fraction, near-surface air temperature, precipitation rate, and low-levels wind speed. Monthly mean fields, time series, and annual cycles of these variables are studied.

\section{a. Incident solar radiation at the surface and column cloud cover fraction}

Figure 1a shows monthly mean values of incident surface solar radiation (averaged over $24 \mathrm{~h}$ ) for January 2003 provided by the original version of the model over South America. For the comparison we used surface solar radiative fluxes derived from satellite radiance measurements. The fluxes were obtained from the Geostationary Operational Environmental Satellite (GOES)-8 visible imagery using a simplified physical model developed at CPTEC (Ceballos et al. 2004). Average values within cells of the model grid of $40 \mathrm{~km}$ are considered. The differences between the model-simulated and satellite-derived monthly mean fluxes are illustrated in Fig. 1b, which reveals a systematic positive difference from +50 to $+100 \mathrm{~W} \mathrm{~m}^{-2}$ between the model-simulated and the satellite-derived fluxes. The errors of satellite-derived fluxes themselves were estimated by the comparison with ground data of $76 \mathrm{Li}-\mathrm{Cor}$ pyranometers located mainly in eastern, central, and southeastern Brazil. A comparison of the Li-Cor pyranometers with more precise instruments showed that those pyranometers are able to yield daily integrated values accurate within a few watts per squared meters (Ceballos et al. 2004). A careful analysis of satellitederived and pyranometer daily irradiations suggests that satellite estimations presented a negative bias during January 2003, with daily averages over the network between -1 and $-18 \mathrm{~W} \mathrm{~m}^{-2}$, with monthly a average of $-11 \mathrm{~W} \mathrm{~m}^{-2}$ and standard deviation of $15 \mathrm{~W} \mathrm{~m}^{-2}$. Therefore, errors in satellite-based estimates were 

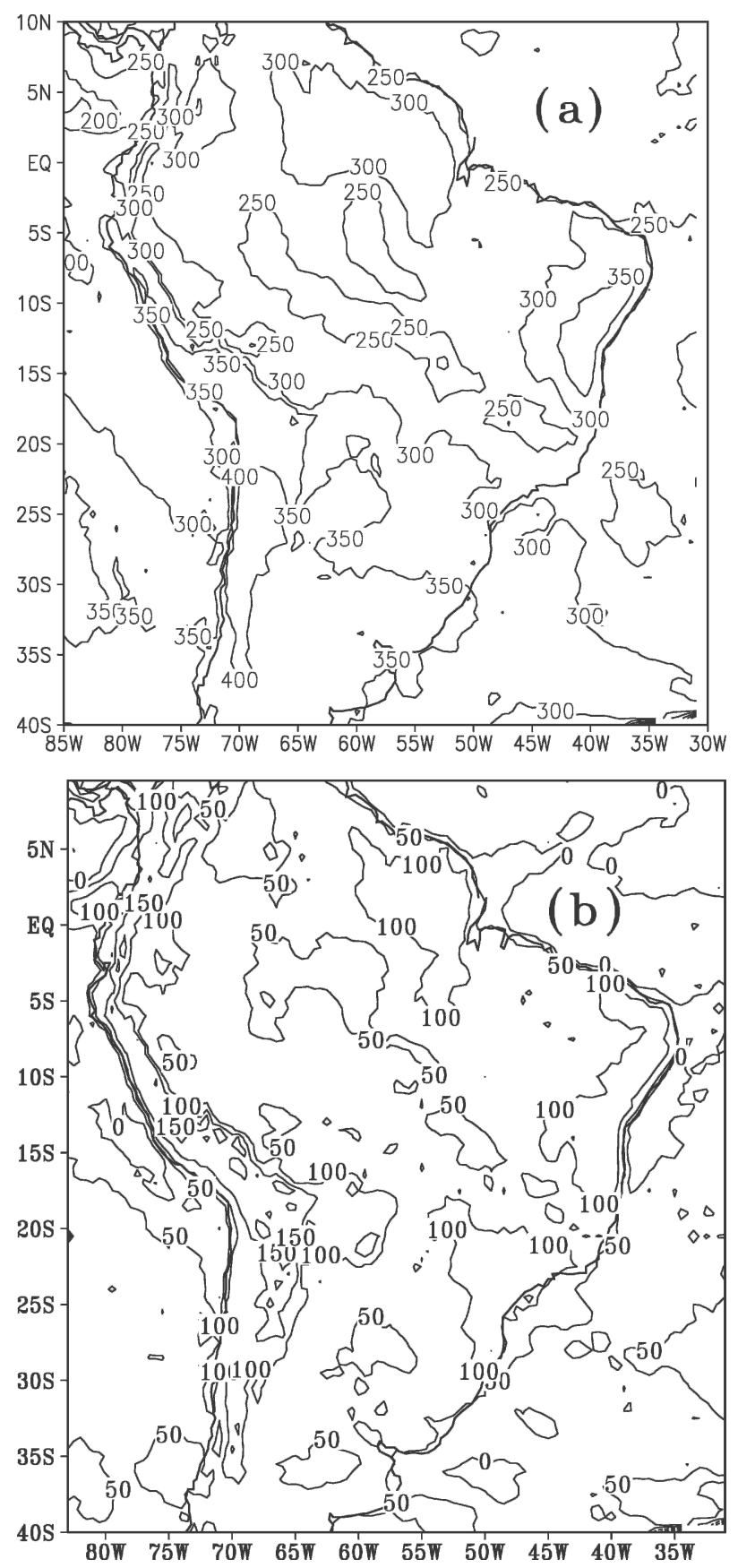

FIG. 1. Mean incident solar radiation at the surface $\left(\mathrm{W} \mathrm{m}^{-2}\right)$ for January 2003 from (a) the original model simulation and (b) the difference between the model-simulated and satellite-derived data.

about $1 / 3-1 / 5$ the size of the difference between Etasimulated and satellite-derived fluxes and could be adopted as reference values.

Over most of the continent the modified version of the model provides smaller values of incident solar radiation at the surface than those provided by the origi- nal model. Hence, these values are in better agreement with the satellite-derived fluxes. Nevertheless, a systematic difference of about $40-60 \mathrm{~W} \mathrm{~m}^{-2}$ still exists, probably because of shortcomings in the description of cloud parameters. The difference between the monthly mean values of incident solar radiation at the surface obtained from the simulations with the modified and original versions of the model is shown in Fig. 2a. Its
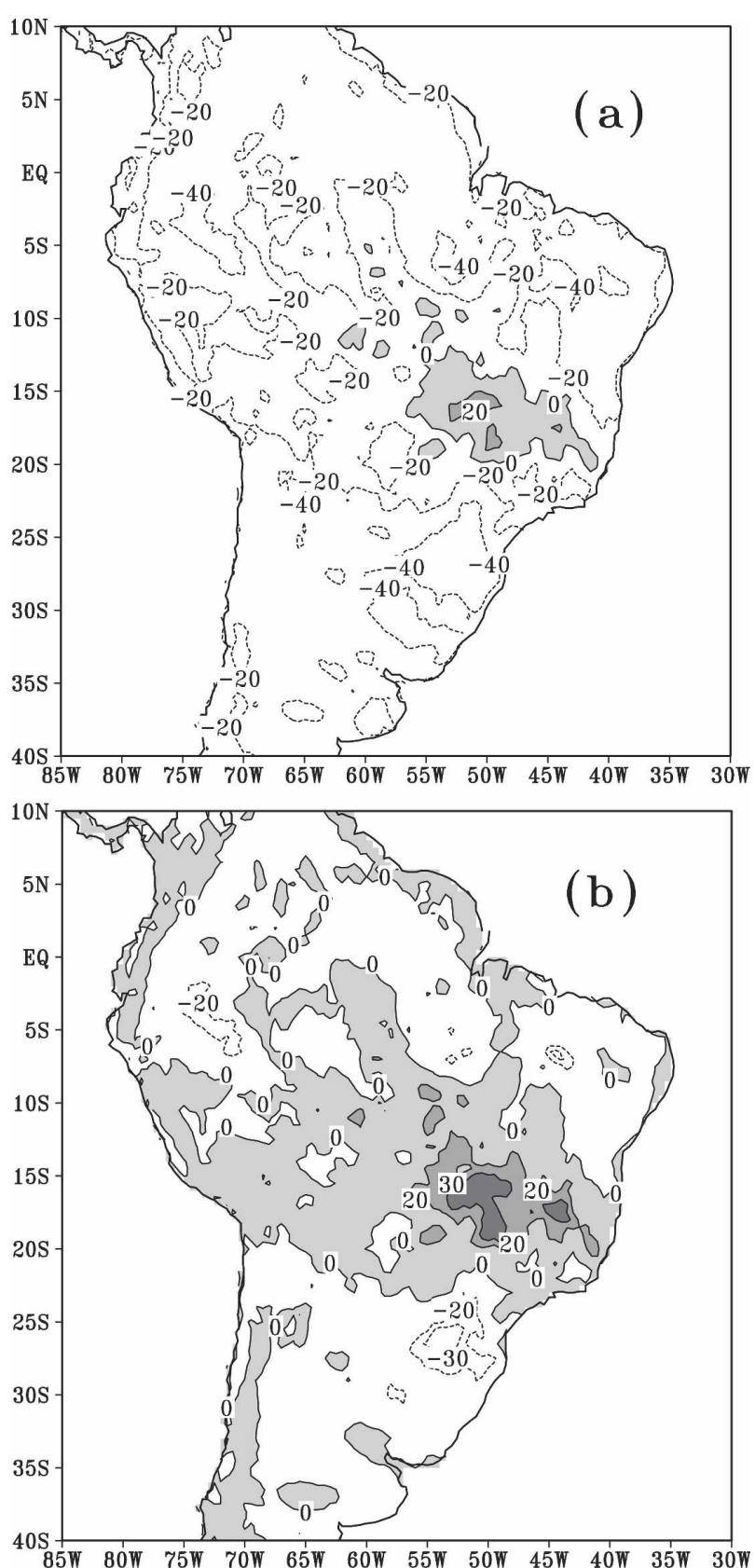

FIG. 2. Difference between modified model and original model simulations of (a) incident and (b) net mean solar radiation at the surface $\left(\mathrm{W} \mathrm{m}^{-2}\right)$ for January 2003. 
magnitude varies from -10 to $-40 \mathrm{~W} \mathrm{~m}^{-2}$ over most part of the continent because of the higher solar radiation absorption in the atmosphere calculated by the new radiation scheme. The positive difference is only seen in the part of the SACZ characterized by extended cloudiness. This difference is related to the schemes difference in cloudiness conditions and because of the decrease of cloud amount in the modified model simulation. Figure $2 b$ shows the same difference in the net (downward minus upward) solar radiation at the surface. The deficiency in the upward flux calculations by the SWR93 scheme leads to the larger region of the positive difference in the net surface solar radiation than in the incident radiation. Note that the difference in the clear-sky solar radiation at the surface is negative over the entire region and varies from -30 to $-40 \mathrm{~W}$ $\mathrm{m}^{-2}$ (not shown). These results, obtained from the simulations with the two model versions, are in accordance with the offline comparison of the original and new solar radiation schemes.

In the Tropics, during the summer, the incident solar radiation at the surface is strongly affected by cloudiness. The principal parameters of cloudiness are cloud cover fraction (CCF) and cloud optical depth. Cloud cover fraction defines the relative area of the model cell covered with clouds. Cloud optical depth defines the extinction and reflection of solar radiation by clouds. Here we analyze cloud cover fraction values provided by the two versions of the model. Figure 3a shows monthly mean CCF of convective clouds in the total atmospheric column obtained from the original model simulation. The largest values are seen in the central and southeastern parts of Brazil where SACZ is usually observed. In the simulation with the modified version, the magnitude of cloud cover fraction decreases in the SACZ. Probably this is caused by the weaker convection resulting from the lower clear-sky solar radiation incoming at the surface. The difference between the CCF values obtained with the modified and original versions of the model is shown in Fig. 3b. The largest negative values are seen in the center of the SACZ, where they reach $30 \%-50 \%$. The difference between nonconvective $\mathrm{CCF}$ values simulated with the two versions is negative in the latitudinal zone from $5^{\circ} \mathrm{N}$ to $10^{\circ} \mathrm{S}$ and positive in the zone from $15^{\circ}$ to $30^{\circ} \mathrm{S}$ (not shown).

The shortwave cloud radiative forcing $(\mathrm{CRF})$ at the surface is an important parameter used to estimate the impact of clouds on surface solar radiation. The cloud radiative forcing is computed as the difference between all- and clear-sky net solar radiation at the surface. Figure 4a presents mean CRF for January 2003 obtained from the original model simulation. The largest values
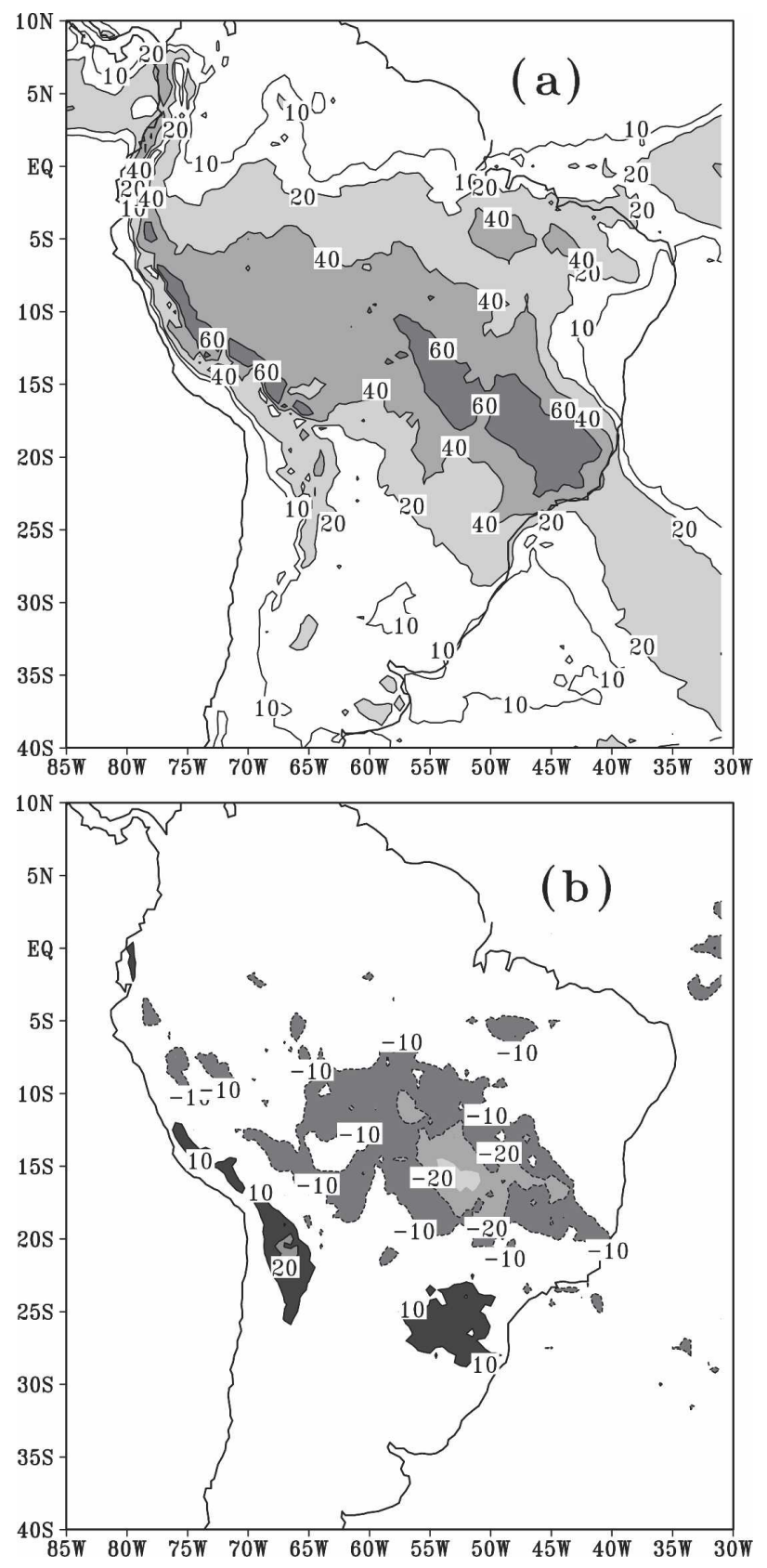

FIG. 3. (a) Mean convective cloud cover fraction (\%) for January 2003 from original model simulation and (b) difference between the modified model and original model simulations of mean cloud cover fraction.

of CRF are about $-100 \mathrm{~W} \mathrm{~m}^{-2}$ and coincide with the largest values of convective cloud cover fraction shown in Fig. 3a. This proves that in the model over the continent the change in net solar surface radiation is mainly determined by the change in the convective cloud cover fraction. The difference in the CRF values between the modified and original model simulations is shown in 

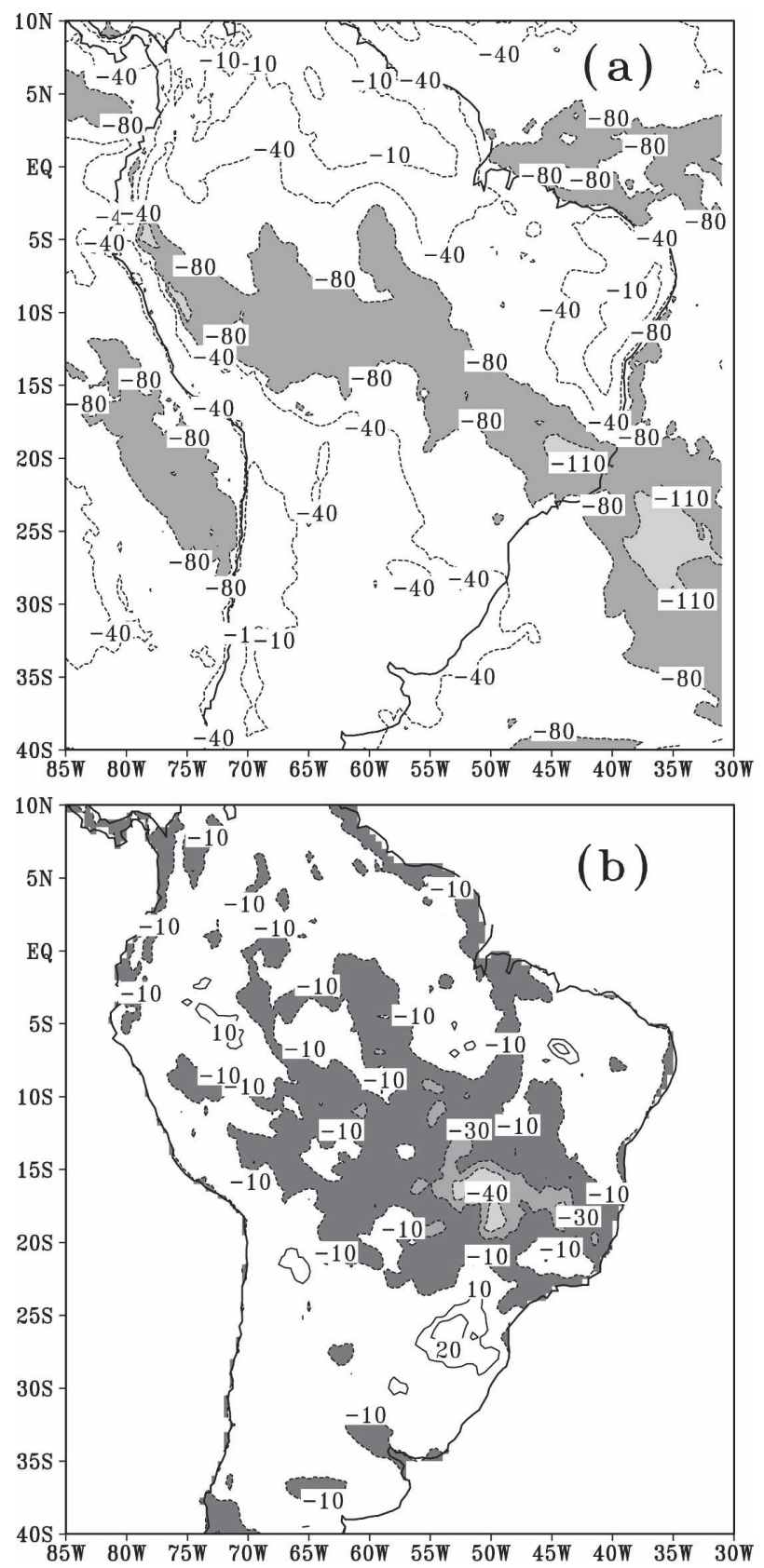

FIG. 4. (a) January 2003 mean shortwave cloud radiative forcing (SWCRF) at the surface $\left(\mathrm{W} \mathrm{m}^{-2}\right)$ and (b) difference in SWCRF values provided by the modified and original models.

Fig. 4b. The modified model provides smaller values of the CRF over most of the continent, except for a small region in the south of Brazil. Comparison of Figs. $3 \mathrm{~b}$ and $4 \mathrm{~b}$ demonstrates that the change in the CRF is because of the change in convective cloud cover fraction.

We selected the three regions in accordance with the different values of convective cloud cover fraction and cloud radiative forcing provided by the model in these regions. The average convective CCF is $46 \%$ in region $2,35 \%$ in region 1 , and $21 \%$ in region 3 (original model simulation). Figure 5 demonstrates the regions selected for the analysis. Region 2 covers part of the continent where extended convective cloudiness associated with the SACZ is observed during summer. Table 5 presents the model-simulated and satellite-derived fluxes averaged over these regions and the difference between them. The original model provides larger values of incident solar radiation at the surface that those derived from satellite measurements for all regions. The simulation with the modified version reduces the difference. The impact of the new radiation scheme is smallest in region 2 , characterized by the dense extended cloudiness. Figure 6 shows the daily mean solar radiative fluxes averaged over the regions. The daily variability of satellite-derived fluxes is well captured by both models, but the systematic difference persists.

Table 6 shows the magnitude of CCF and CRF provided by the original and modified versions of the model and averaged over the selected regions. Both the CCF of convective cloudiness and the CRF averaged over region 2 are smaller by $26 \%-30 \%$ in the integration with the modified version than in the original. The higher values of CCF of nonconvective cloudiness obtained with the modified version in region 2 do not affect incident surface solar radiation because of the preference made in the model cloud cover scheme. The

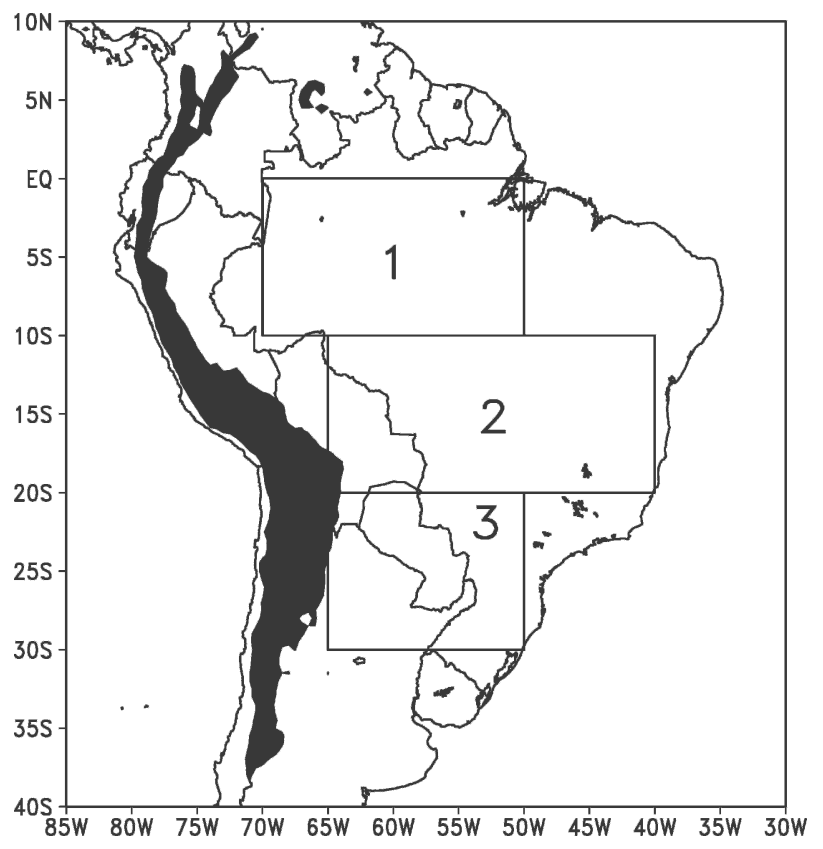

FIG. 5. The regions selected for the analysis of the modelsimulated and observed ground fluxes and meteorological variables. 
TABLE 5. Mean incident solar radiation at the surface $\left(\mathrm{W} \mathrm{m}^{-2}\right)$ for January 2003, averaged over the three regions; Sat: satellitederived data; Ori: original model simulation; Mod: modified model simulation; Org - Sat, Mod - Sat, Org - Mod: absolute (relative) differences.

\begin{tabular}{ccccccc}
\hline \hline Region & Sat & Ori & Mod & $\begin{array}{c}\text { Ori }- \\
\text { Sat }\end{array}$ & $\begin{array}{c}\text { Mod }- \\
\text { Sat }\end{array}$ & $\begin{array}{c}\text { Mod }- \\
\text { Ori }\end{array}$ \\
\hline 1 & 203 & 269 & 246 & $+66(32 \%)$ & $+43(21 \%)$ & $-23(9 \%)$ \\
2 & 202 & 282 & 275 & $+80(40 \%)$ & $+73(36 \%)$ & $-7(2 \%)$ \\
3 & 256 & 338 & 306 & $+82(32 \%)$ & $+50(20 \%)$ & $-32(9 \%)$ \\
\hline
\end{tabular}

scheme uses only convective CCF if both the convective and nonconvective cloudiness with CCF greater than $10 \%$ coexist in the same layer. The largest difference of about $37 \%$ between the nonconvective CCF values, provided by the modified and original versions, is seen in region 3.

The change in the incident solar radiation at the surface causes the change in the surface flux balance.
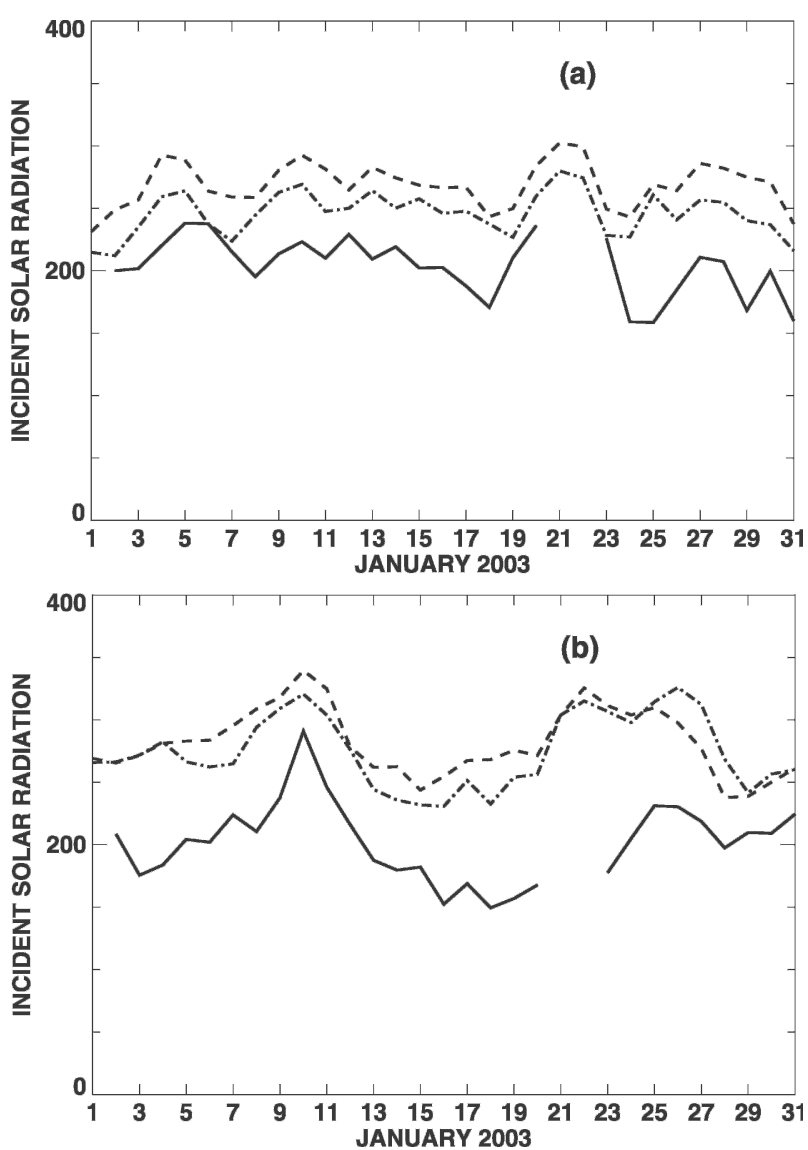

FIG. 6. Daily mean incident solar radiation at the surface (W $\mathrm{m}^{-2}$ ) for January 2003, averaged over (a) region 1 and (b) region 2 for the original model simulation (dashed), modified model simulation (dot-dashed), and satellite-derived dataset (solid).
TABLE 6. Mean CCF and CRF at the surface for January 2003, averaged over the three regions; Con: convective CCF; Ncon: nonconvective CCF; Ori: original model simulation; Mod: modified model simulation.

\begin{tabular}{|c|c|c|c|c|c|c|}
\hline \multirow[b]{3}{*}{ Region } & \multicolumn{4}{|c|}{ CCF (\%) } & \multicolumn{2}{|c|}{$\mathrm{CRF}\left(\mathrm{W} \mathrm{m} \mathrm{m}^{-2}\right)$} \\
\hline & \multicolumn{2}{|c|}{ Con } & \multicolumn{2}{|c|}{ Ncon } & \multirow[b]{2}{*}{ Ori } & \multirow[b]{2}{*}{ Mod } \\
\hline & Ori & Mod & Ori & Mod & & \\
\hline 1 & 35 & 30 & 53 & 41 & -61 & -51 \\
\hline 2 & 46 & 34 & 59 & 61 & -70 & -49 \\
\hline 3 & 21 & 25 & 33 & 52 & -36 & -34 \\
\hline
\end{tabular}

Table 7 shows latent and sensible heat fluxes obtained from the modified and original model simulations and averaged over the region. The change in the absolute values of the latent heat flux between the modified and original model simulations is related to the change in the temperature and humidity of the atmosphere and the soil. As was shown in the previous studies, the Eta Model overestimates latent and sensible heat fluxes at the surface (Hinkelman et al. 1999; Chou et al. 2002). Hence, these fluxes are also improved in the modified model simulation.

\section{b. Near-surface air temperature and precipitation}

The January 2003 mean air temperature obtained from the original model simulation at the height of $2 \mathrm{~m}$ above the surface is presented in Fig. 7a. For the validation of model-simulated temperature we used observational data obtained at the meteorological stations of South America. The description of the data is given online at http://www.cptec.inpe.br/. The data of about 1500 synoptic and automatic weather stations are utilized. Most of the stations are located in the east of Brazil. Figure $7 \mathrm{~b}$ shows the observed mean near-surface air temperature for January 2003 interpolated at the $1^{\circ} \times 1^{\circ}$ grid. One can see from the comparison of Figs. $7 \mathrm{a}$ and $7 \mathrm{~b}$ that the temperature values given by the original model version are lower in the north of Brazil and higher in the central part of the continent as compared with the observations. The difference is not reduced in the simulation with the modified version.

TABLE 7. Mean latent ( $\mathrm{LH})$ and sensible ( $\mathrm{SH}$ ) heat fluxes at the surface for January 2003, averaged over the three regions; Ori: original model simulation; Mod: modified model simulation.

\begin{tabular}{cccccc}
\hline & \multicolumn{2}{c}{$\mathrm{LH}\left(\mathrm{W} \mathrm{m}^{-2}\right)$} & & \multicolumn{2}{c}{$\mathrm{SH}\left(\mathrm{W} \mathrm{m}^{-2}\right)$} \\
\cline { 2 - 3 } \cline { 6 - 6 } Region & Ori & Mod & & Ori & Mod \\
\hline 1 & -120 & -107 & & -60 & -53 \\
2 & -128 & -116 & & -44 & -45 \\
3 & -132 & -118 & & -57 & -49 \\
\hline
\end{tabular}



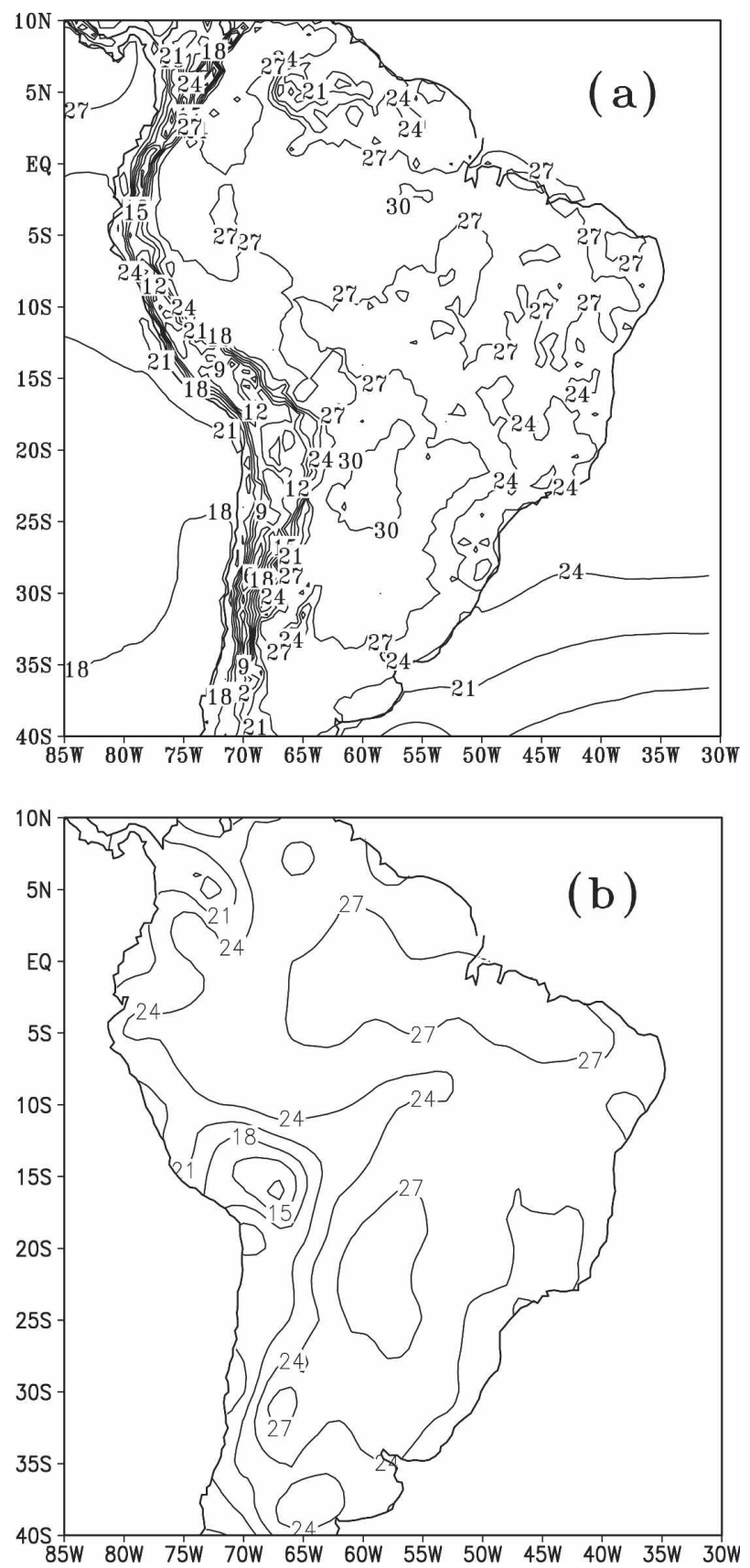

FIG. 7. Mean 2-m air temperature $\left({ }^{\circ} \mathrm{C}\right)$ for January 2003 from the (a) original model simulation and (b) meteorological stations over South America.

Figure 8 shows the difference between the temperature fields provided by the modified and original versions. The difference is negative over most of the continent, probably because of the lower net solar radiation at the surface in the modified model simulation (Fig. 2b). It is positive over region 2 because of the higher net solar radiation provided by the modified version over the

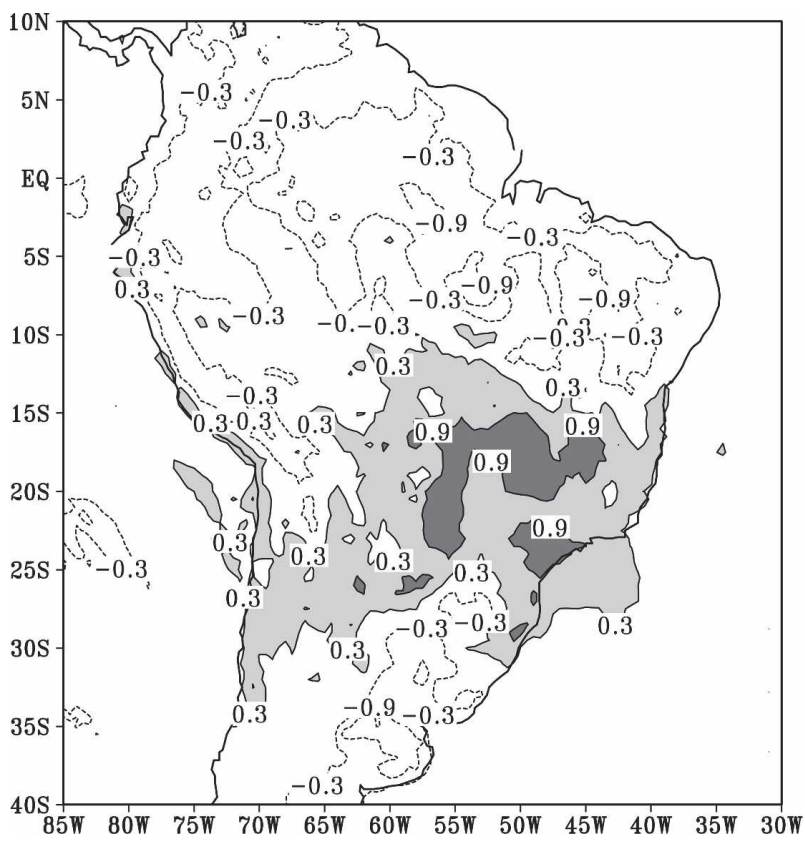

FIG. 8. Difference between modified model and original model simulations of mean 2-m air temperature $\left({ }^{\circ} \mathrm{C}\right)$ for January 2003.

region. Note that other physical processes such as advection also affect the surface air temperature. The positive change in the surface air temperature in region 3 can be related to the stronger transport of the warm and humid air from the north to this region in the modified model simulation (section 4d). The monthly mean near-surface air temperature averaged over the selected regions is shown in Table 8. The difference between the temperature values obtained from the simulations with the two model versions is about $0.4^{\circ} \mathrm{C}$ for all regions.

Figure 9a presents monthly mean daily accumulated precipitation in the original model simulation. The largest values of precipitation are seen in the SACZ. Figure $9 \mathrm{~b}$ shows the difference between the precipitation values obtained from the simulations with the two model versions. In the SACZ, the modified version provides precipitation values that are smaller by $20 \%-30 \%$ as

TABLE 8 . Mean 2-m air temperature $T$ and precipitation rate $P$ for January 2003, averaged over the three regions; Ori: original model simulation; Mod: modified model simulation; GPCP: Global Precipitation Climatology Project dataset.

\begin{tabular}{ccccccc}
\hline & \multicolumn{2}{c}{$T\left({ }^{\circ} \mathrm{C}\right)$} & & \multicolumn{3}{c}{$P\left(\mathrm{~mm} \mathrm{day}^{-1}\right)$} \\
\cline { 2 - 3 } \cline { 6 - 7 } Region & Ori & Mod nnnyyyn & & Ori & Mod & GPCP \\
\hline 1 & 27.7 & 27.3 & & 5.7 & 4.8 & 6.4 \\
2 & 26.1 & 26.5 & & 8.1 & 5.7 & 9.1 \\
3 & 27.7 & 28.1 & & 4.5 & 4.6 & 6.7 \\
\hline
\end{tabular}



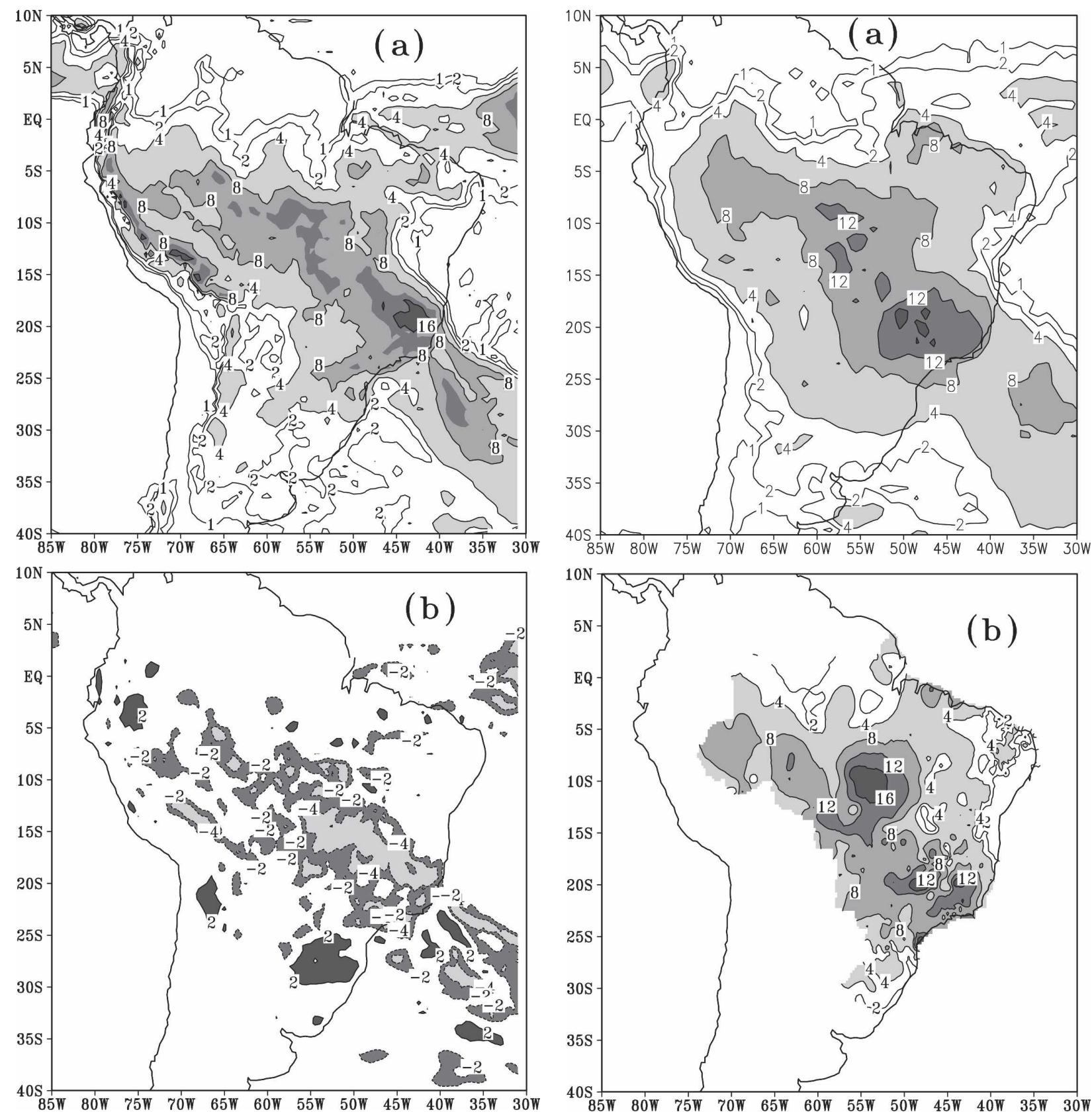

FIG. 9. Mean precipitation $\left(\mathrm{mm} \mathrm{day}^{-1}\right)$ for January 2003 from the (a) original model simulation and (b) difference between the modified model and original model simulations.

compared with the original. For the validation of the model-simulated precipitation we used the data available from the Global Precipitation Climatology Project (GPCP) (Huffman et al. 2001) with the spatial resolution of $1^{\circ} \times 1^{\circ}$. This is a combined observation-only gridded dataset based on gauge measurements and satellite estimates of rainfall. Figure 10a shows the GPCP mean precipitation for January 2003. Figure 10b pre-

FIG. 10. Mean precipitation $\left(\mathrm{mm} \mathrm{day}^{-1}\right.$ ) for January 2003 from (a) GPCP datasets and (b) observations at meteorological stations over Brazil.

sents mean precipitation values obtained at the meteorological stations of Brazil and interpolated at the $0.25^{\circ}$ $\times 0.25^{\circ}$ grid. (A description of the data is given online at http://cptec.inpe.br/.) One can see from Figs. 9a, 9b, and 10a that over the continent the GPCP precipitation data are in a better agreement with the original model precipitation than with the precipitation provided by the modified model. This means that convection and 

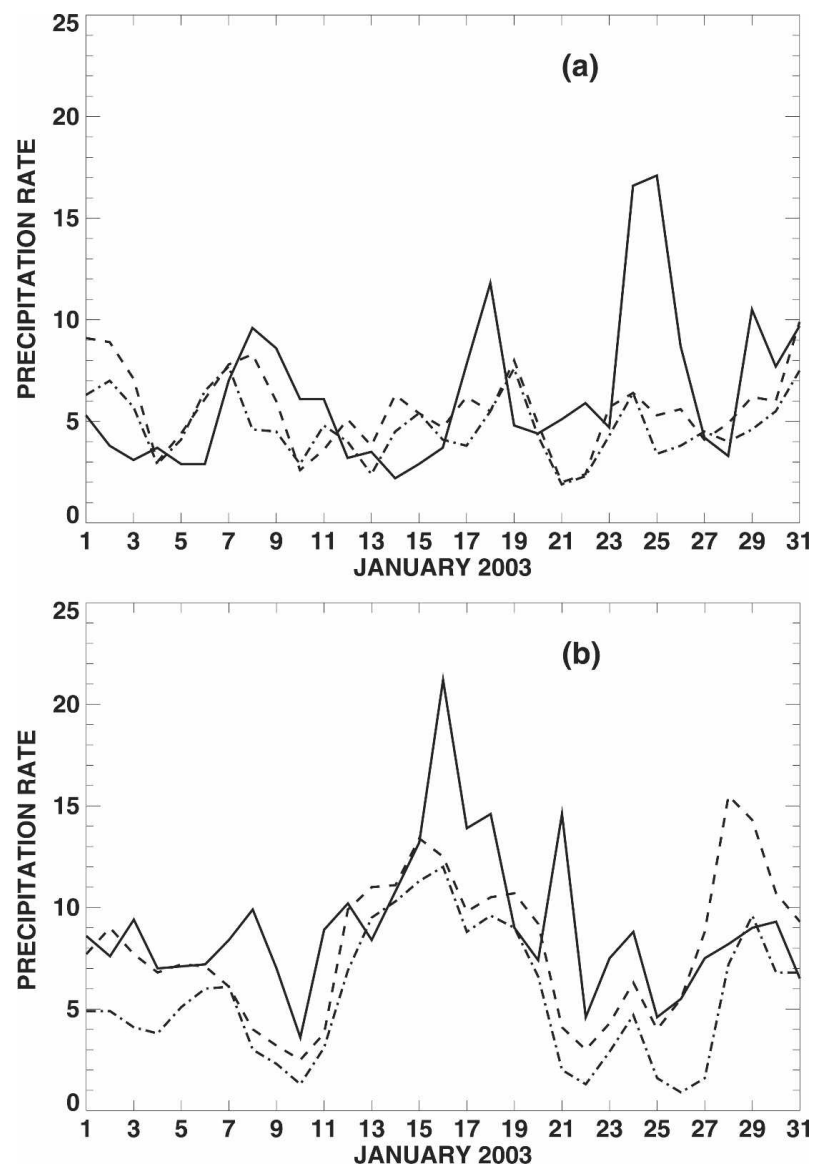

FIG. 11. Daily precipitation $\left(\mathrm{mm} \mathrm{day}^{-1}\right)$ for January 2003 averaged over (a) region 1 and (b) region 2 for the original model simulation (dashed), modified model simulation (dot-dashed), and GPCP datasets (solid).

land surface schemes in the modified version have to be also modified to be more consistent with the new radiation scheme. Over the Andes and Atlantic Ocean, the modified version gives closer results to those of the GPCP data. Note that the difference between the observational data themselves (GPCP and meteorological stations) is noticeable.

The daily variations of precipitation averaged over the three selected regions are shown in Fig. 11. The values provided by the two model versions are compared with the GPCP data. One can see that both versions capture observed daily variations of precipitation. Nevertheless, the precipitation for the high-rainfall days is underestimated. The mean precipitation for January 2003 averaged over the selected regions is presented in Table 8 . The values obtained from the modified model simulation for regions 1 and 2 are lower by $16 \%-30 \%$ as compared with the original model simulation, and are lower by $25 \%-37 \%$ as compared with the GPCP data. Therefore, the implementation of new radiation scheme requires changes in other physical parameterizations of the model for better representation of precipitation over the continent.

\section{c. Diurnal cycle of precipitation and cloud cover fraction}

The ability of the model to reproduce a diurnal cycle of precipitation and cloudiness characterizes a quality of parameterizations of physical processes in the model. The review of numerous observational evidence of the pronounced precipitation diurnal cycle in the Tropics is given by Yang and Slingo (2001). Most studies demonstrate that the maximum of precipitation occurs early in the morning over the oceans and after noon over the continents. Over the continents (far from oceans or mountains) the precipitation diurnal cycle is mainly related to the diurnal cycle of incident solar radiation and to convection. The daily variations of convective cloud cover fraction and precipitation have to follow each other.

Figures 12 and 13 show that region 2 is characterized by strong precipitation with a profound diurnal cycle. The magnitude of precipitation is smaller and its diurnal cycle is less intense for region 1 than for region 2 . Region 3 is characterized by a smooth diurnal cycle of precipitation. The average convective cloud cover fraction is equal to $46 \%$ in region $2,35 \%$ in region 1 , and $21 \%$ in region 3 (original model simulation). Thus, the conditions needed for the development of convection (such as humidity of the atmosphere, influx of humidity, air vertical velocity) are different in these regions. The difference in the diurnal cycle of precipitation for the regions means different sensitivities of the convection to the diurnal cycle of incident solar radiation. The sensitivity is higher for region 2 than for region 1 ; it is low for region 3. Therefore, the impact of the new scheme on the convection has to be larger in region 2 than in region 1 and has to be larger in region 1 than in region 3 .

The clear-sky net (downward minus upward) solar radiation at the surface decreases for all regions in the simulation with the new scheme. The difference in the clear-sky net solar radiation between the modified and original model simulations is shown in Table 9. The smaller clear-sky net solar radiation at the surface affects the surface temperature and the convection in regions 2 and 1 . Both precipitation and convective cloud cover fraction decreases. The impact is larger in region 2 than in region 1 in accordance with the abovementioned statements. Because of the impact of convective cloudiness the difference in the all-sky net solar radiation at the surface became smaller in region 1 and positive in region 2 as compared with the clear-sky 

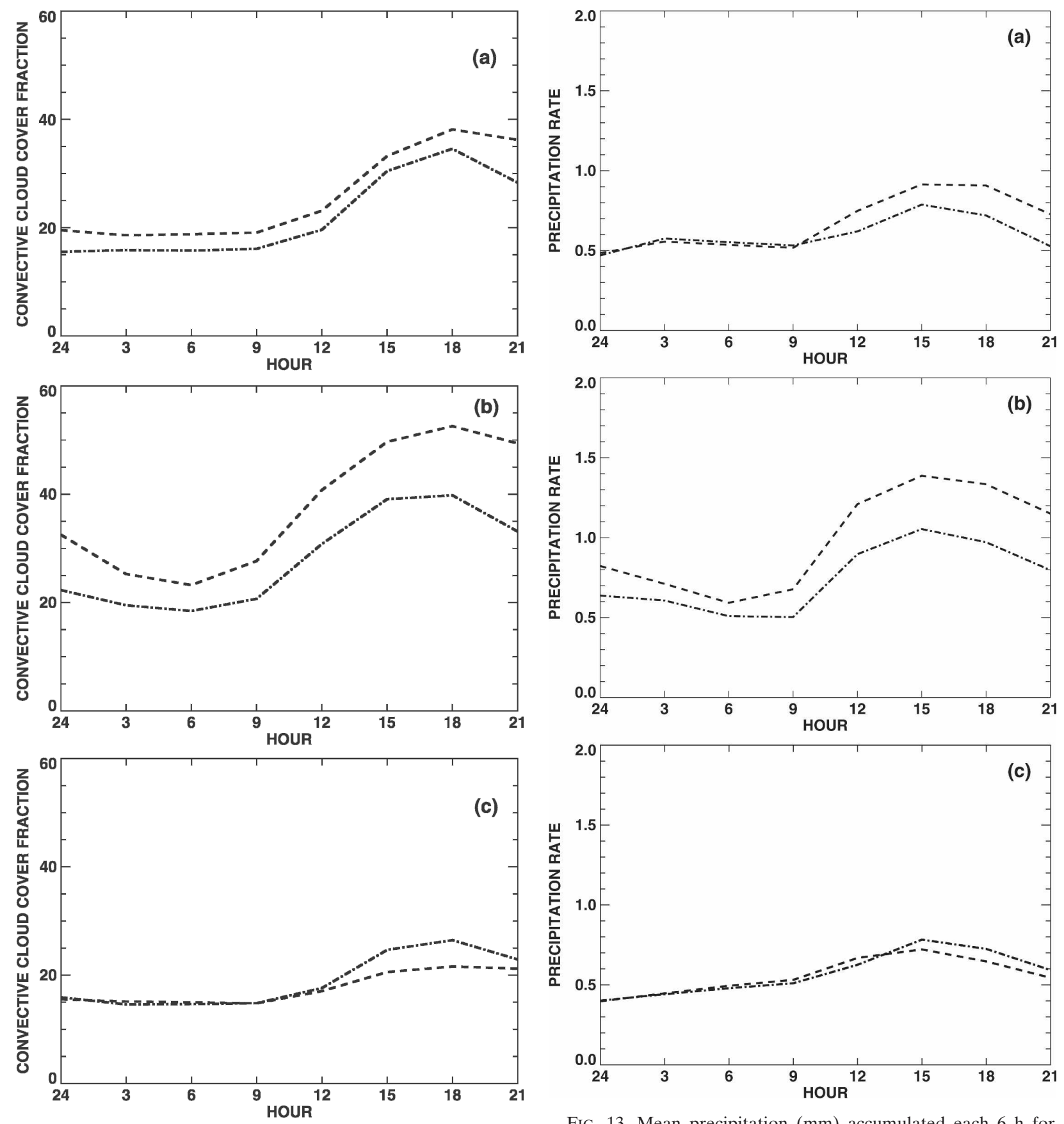

FIG. 12. Mean diurnal cycle of convective cloud cover fraction (\%) for January 2003 averaged over (a) region 1, (b) region 2, and (c) region 3 for the original model simulation (dashed) and modified model simulation (dot-dashed) (hours: LST).

fluxes. The change in the all-sky net solar radiation at the surface is probably responsible for the negative change in the near-surface air temperature in region 1 and for the positive change in region 2. Note that other physical processes such as advection, can also affect near-surface air temperature. In region 3 , the precipi-

FIG. 13. Mean precipitation ( $\mathrm{mm}$ ) accumulated each $6 \mathrm{~h}$ for January 2003, averaged over (a) region 1, (b) region 2, and (c) region 3 for the original model simulation (dashed) and modified model simulation (dot-dashed) (hour: LST).

tation values are slightly sensitive to the diurnal cycle of solar radiation. This explains the small impact of the new radiation scheme on the precipitation shown in Fig. 13c. It is probable that some increase of precipitation and surface air temperature in this region is related to the stronger transport of warm and humid air from 
TABLE 9. Difference in January 2003 mean clear-sky net solar radiation at the surface (CSW), all-sky net solar radiation (SW), CRF, convective CCF, 2-m air temperature $(T)$, daily accumulated precipitation $(P)$, and precipitable water in the atmosphere column $(\mathrm{PW})$ between the modified and original model simulations.

\begin{tabular}{cccccccc}
\hline \hline Region & $\mathrm{CSW}\left(\mathrm{W} \mathrm{m}^{-2}\right)$ & $\mathrm{SW}\left(\mathrm{W} \mathrm{m}^{-2}\right)$ & $\mathrm{CRF}\left(\mathrm{W} \mathrm{m}^{-2}\right)$ & $\mathrm{CCF}(\%)$ & $T\left({ }^{\circ} \mathrm{C}\right)$ & $P\left(\mathrm{~mm} \mathrm{day}^{-1}\right)$ & $\mathrm{PW}\left(\mathrm{kg} \mathrm{m}^{-2}\right)$ \\
\hline 1 & -11 & -1 & +10 & -5 & -0.4 & -0.9 & -0.5 \\
2 & -8 & +13 & +21 & -12 & +0.4 & -2.4 & -0.5 \\
3 & -10 & -8 & +2 & +4 & +1.0 & +0.1 & +2.6 \\
\hline
\end{tabular}

the north in the modified model simulation (section $4 d$ ). Table 9 shows that the modified model provides in region 3 a larger value of the precipitable water in the atmosphere column as compared with the original model.

\section{d. Low-level wind fields and meridional wind speed profiles}

The 925-hPa mean wind fields for January 2003 obtained from the integration with the original version, the modified version, and the reanalysis data are given in Figs. 14a, 14b, and 15, respectively. The NCEP-DOE Reanalysis-II data (T62/L28; Kanamitsu et al. 2002) were used for the comparison. All of the datasets demonstrate a southward low-level current to the east of the Andes. The magnitude of wind speed in the current located in the latitudinal zone from $15^{\circ}$ to $25^{\circ} \mathrm{S}$ is larger in the original model simulation than in the reanalysis data, and is larger in the modified model simulation than in the original model simulation. The difference between the model results and reanalysis can be explained by the more realistic topography of the Eta Model and by its ability to simulate processes of smaller scales than those resolved by the reanalysis data. The distinction of the physical parameterizations of the Eta Model and GCM that is used for preparation of the reanalysis can also contribute to this difference (Vernekar et al. 2003). The comparison of the two modelsimulated datasets with wind speed measurements can show which dataset is closer to the observations.

The South American Low-Level Jet Experiment (SALLJEX) is an internationally coordinated effort aimed at studying the role of the South American lowlevel jet (LLJ) in moisture and energy exchange between the Tropics and extratopics. The experiment was conducted from December 2002 to March 2003. The results of the experiment and previous studies using global reanalysis and isolated observations show that the core of the low-level jet is located at the 925- and $850-\mathrm{hPa}$ levels near Santa Cruz $\left(17^{\circ} 45^{\prime} \mathrm{S}, 63^{\circ} 08^{\prime} \mathrm{W}\right)$ and Trinidad $\left(14^{\circ} 49^{\prime} \mathrm{S}, 64^{\circ} 54^{\prime} \mathrm{W}\right)$ in Bolivia (Saulo et al. 2000; Seluchi and Marengo 2000; Marengo et al. 2002, 2004). For the comparison with the model-simulated wind profiles we used high-resolution upper-air observations conducted near Santa Cruz in January 2003. Rawinsondes were generally released twice per day at 0600 and 1800 UTC from 16 to 31 January.

We used the criterion of Bonner (1968) to estimate the ability of the model to reproduce LLJ events. This criterion specifies that in LLJ a maximum of the wind speed profile has to reach at least $12 \mathrm{~m} \mathrm{~s}^{-1}$ within 1.5 $\mathrm{km}$ above the ground and the rate of decrease (gradient) of the wind speed above the jet has to be larger than $6 \mathrm{~m} \mathrm{~s}^{-1} \mathrm{~km}^{-1}$. Figures $16 \mathrm{a}$ and $16 \mathrm{~b}$ present the time series of meridional wind $(0000,0600,1200,1800$, 2400 UTC) at $850-$ and 925 -hPa levels obtained from the model output and reanalysis at the grid point nearest to the Santa Cruz station. The data obtained from upper-air sounding at Santa Cruz are also shown. Figure 17 presents the vertical gradient of the meridional wind speed between the 850 - and $700-\mathrm{hPa}$ levels for the same datasets. From the upper-air observations the LLJ event is detected on 20-21 January 2003. Observed meridional wind speed at 850 and $925-\mathrm{hPa}$ levels and wind gradient (850-700 $\mathrm{hPa}$ ) during these days correspond to Bonner's (1968) criterion. Figures 16 and 17 show that the reanalysis and both versions of the Eta Model underestimate the low-level wind speed and 850-700-hPa wind speed gradient observed during the event. On the whole, the modified version of the model gives closer values of the low-level wind speed to the observations at Santa Cruz for the period from 16 January to 31 January 2003 as compared with the original model simulation.

\section{Summary and conclusions}

A new solar radiation scheme has been implemented into the Eta Model in order to improve its surface flux representation and to evaluate related changes in the meteorological variables of the model. The accuracy of the original and the new solar radiation schemes is estimated offline from a comparison with a detailed lineby-line method. In clear-sky conditions, the difference between the original scheme and the LBL method is about $70 \mathrm{~W} \mathrm{~m}^{-2}$ in incident surface solar radiation and 

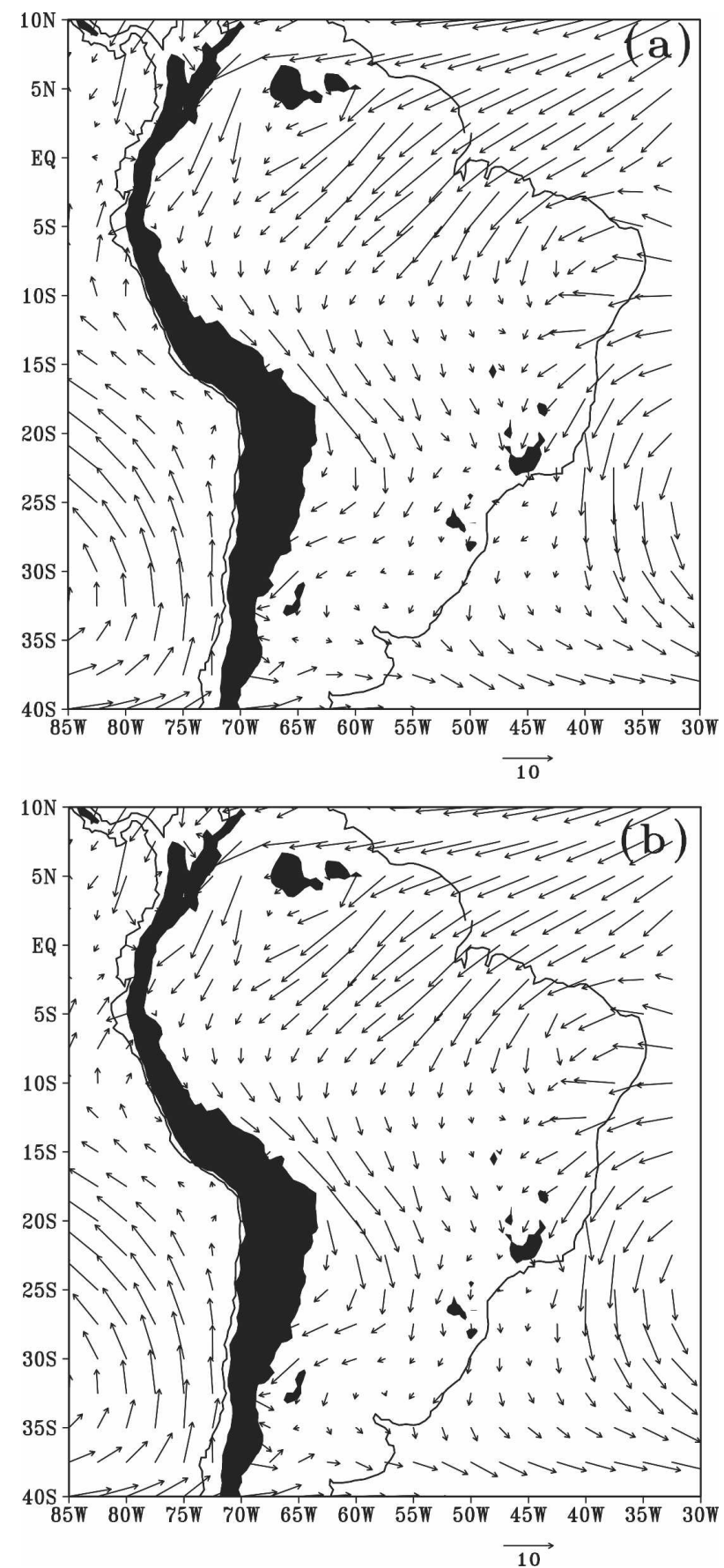

FIG. 14. Mean 925-hPa wind ( $\mathrm{m} \mathrm{s}^{-1}$ ) for January 2003 from the (a) original model simulation and (b) modified model simulation.

$25-50 \mathrm{~W} \mathrm{~m}^{-2}$ in atmospheric absorption. The same difference estimated for the new radiation scheme is $1-2$ $\mathrm{W} \mathrm{m}{ }^{-2}$. In cloudy conditions, the difference obtained for the original scheme varies from 60 to $-70 \mathrm{~W} \mathrm{~m}^{-2}$ and for the new scheme is less then $8 \mathrm{~W} \mathrm{~m}^{-2}$. Thus, the new radiation scheme demonstrates a higher accuracy

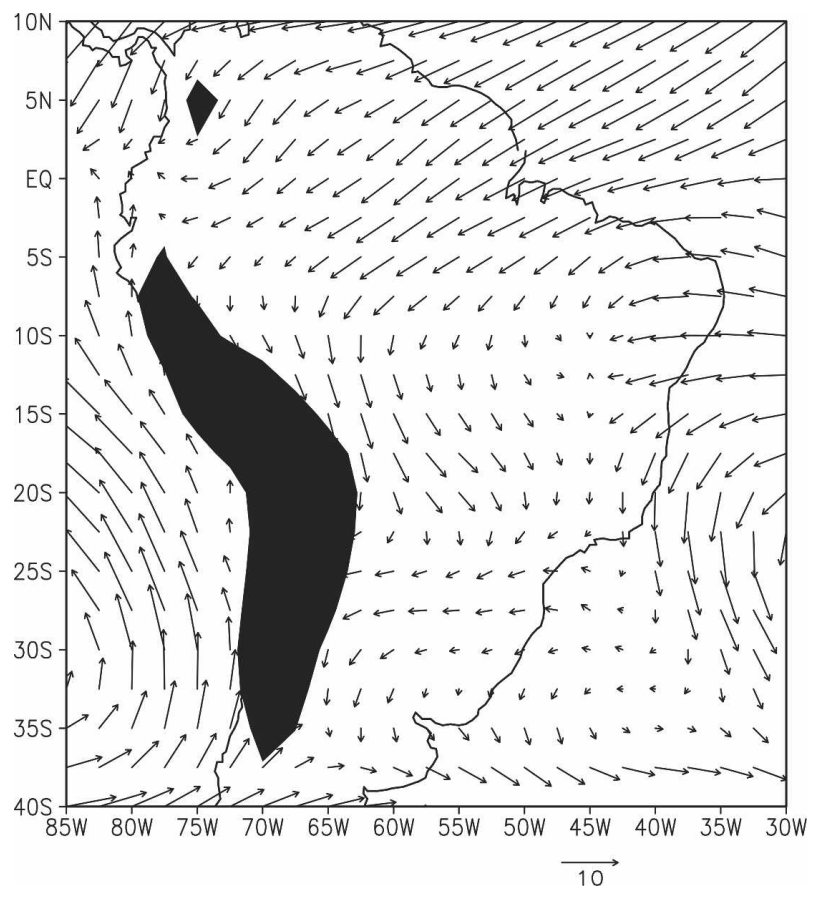

FIG. 15. Mean 925-hPa wind $\left(\mathrm{m} \mathrm{s}^{-1}\right)$ for January 2003 from reanalysis datasets.

in both clear-sky and cloudy atmospheric conditions as compared with the LBL method.

The two versions of the model, with the original and new radiation schemes, were integrated for January 2003 with reanalysis as initial and lateral boundary conditions. The output fields are compared with each other and with observational data. The incident solar radiation at the surface provided by the version with the new radiation scheme is in a better agreement with the satellite-derived data. Nevertheless, a systematic difference remains $(10 \%-20 \%)$, probably because of the incorrect description of cloud parameters in the model. The lower incident solar radiation simulated by the modified version causes a decrease of near-surface air temperature of $0.1^{\circ}-1^{\circ} \mathrm{C}$ over most of the continent and a decrease of precipitation rate of $20 \%-30 \%$ over the SACZ. The increase of the incident solar radiation and temperature is obtained in the center of the SACZ because of the effect of cloudiness. Some increase of the precipitation rate appears to the south of Brazil. Over the continent, the original version of the model reproduces a monthly mean precipitation rate closer to the GPCP observational data as compared with the modified version. Reanalysis and both versions of the model underestimate the low-level wind speed and 850-700$\mathrm{hPa}$ wind speed gradient at the Santa Cruz observational site during the LLJ event as compared with the observations. 

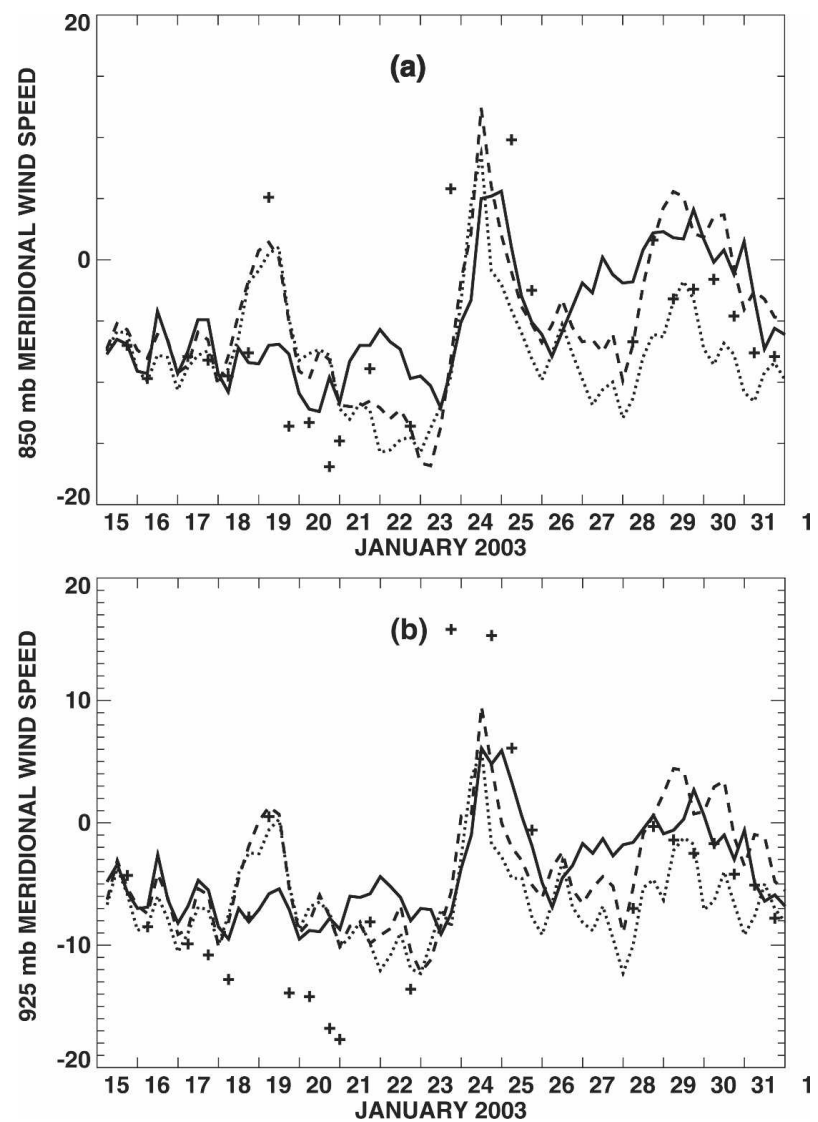

FIG. 16. The (a) 850- and (b) 925-hPa meridional wind speed $\left(\mathrm{m} \mathrm{s}^{-1}\right)$ obtained each $6 \mathrm{~h}$ at the observational site at Santa Cruz $\left(17^{\circ} 23^{\prime} \mathrm{S}, 63^{\circ} 46^{\prime} \mathrm{W}\right)$ for the reanalysis data (solid), original model simulation (dashed), modified model simulation (dotted), and upper-air sounding data (pluses).

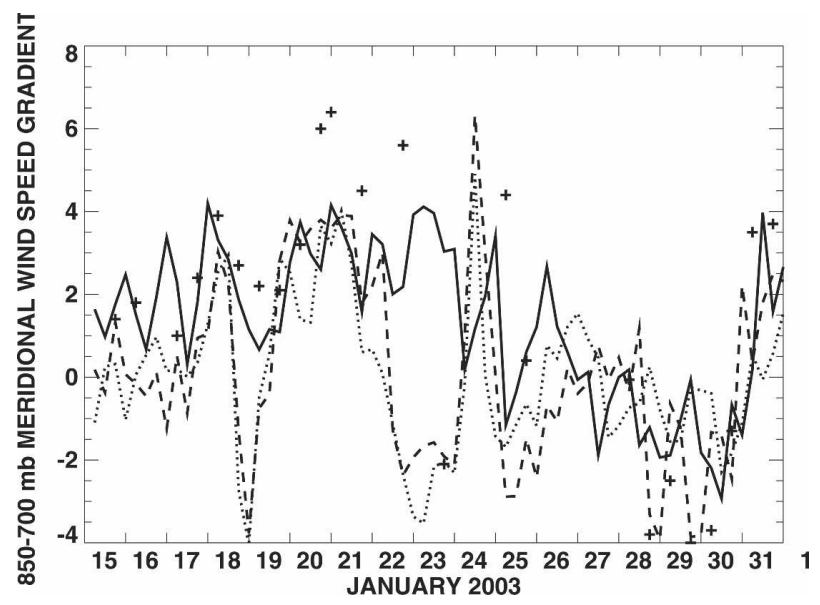

FIG. 17. Meridional wind speed gradient $\left(\mathrm{m} \mathrm{s}^{-1} \mathrm{~km}^{-1}\right)$ between the levels of 850 and $700 \mathrm{hPa}$ obtained each $6 \mathrm{~h}$ at the observational site at Santa Cruz $\left(17^{\circ} 23^{\prime} \mathrm{S}, 63^{\circ} 46^{\prime} \mathrm{W}\right)$ for the reanalysis data (solid), original model simulation (dashed), modified model simulation (dotted), and upper-air sounding data (pluses).
Comparison of the model-simulated ground fluxes and meteorological variables with observations demonstrates that implementation of a new radiation scheme improves surface flux representation over the entire region of the model integration as compared with satellite-derived data. Precipitation is improved over the oceans and the Andes, but it diverges with the observations over the continent. The difference between the observed near-surface air temperature values and those provided by the modified model is also noticeable. Therefore, the change of the solar radiation scheme in the model requires further changes in others physical parameterizations of the model aimed to obtain better model performance. The analysis of the impact of each physical parameterization on the model simulation results can help to use all new parameterizations together.

Acknowledgments. Author T. A. Tarasova was supported by a grant of the Brazilian scientific foundation-FAPESP (N2002/12395-5). The data obtained during the field experiment SALLJEX (FAPESP Project N01/13816-1) were used in the study.

\section{REFERENCES}

Arakawa, A., and V. R. Lamb, 1977: Computational design of the basic dynamical processes of the UCLA general circulation model. Methods Comput. Phys., 17, 173-265.

Betts, A. K., and M. T. Miller, 1986: A new convective adjustment scheme. Part II: Single column tests GATE wave, BOMEX, and Arctic air-mass data. Quart. J. Roy. Meteor. Soc., 112, 693-703.

Black, T. L., 1994: NMC notes: The new NMC Mesoscale Eta Model: Description and forecast examples. Wea. Forecasting, 9, 256-278.

Bonner, W. D., 1968: Climatology of the low level jet. Mon. Wea. Rev., 96, 833-850.

Ceballos, J. C., M. J. Bottino, and J. M. de Souza, 2004: A simplified physical model for assessing solar radiation over Brazil using GOES 8 visible imagery. J. Geophys. Res., 109, D02211, doi:10.1029/2003JD003531.

Chen, F. K., Z. Janjic, and K. Mitchel, 1997: Impact of the atmospheric surface-layer parameterizations in the new landsurface scheme of the NCEP Mesoscale Eta Model. Bound.Layer Meteor., 85, 391-421.

Chou, M.-D., and M. J. Suarez, 1999: A solar radiation parameterization (CLIRAD-SW) for atmospheric studies. NASA Tech. Rep. NASA/TM-1999-10460, vol. 15, 38 pp.

Chou, S. C., A. M. B. Nunes, and I. F. A. Cavalcanti, 2000: Extended ranges forecasts over South America using the regional eta model. J. Geophys. Res., 105, 10 147-10 160.

— C. A. S. Tanajura, Y. Xue, and C. A. Nobre, 2002: Validation of the coupled Eta/SSiB Model over South America. $J$. Geophys. Res., 107, 8088, doi:10.1029/2000JD000270.

Clough, S. A., F. X. Kneizys, and R. W. Davies, 1989: Line shape and the water vapor continuum. Atmos. Res., 23, 229-241.

Figueroa, S. N., P. Satyamurty, and P. L. da Silva Dias, 1995: Simulations of the summer circulation over the South Ameri- 
can Region with the Eta coordinate model. J. Atmos. Sci., 52, 1573-1584.

Fels, S. B., and M. D. Schwartzkopf, 1975: The simplified exchange approximation: A new method for radiative transfer calculations. J. Atmos. Sci., 32, 1475-1488.

Ferrier, B. S., Y. Jin, Y. Lin, T. Black, E. Rogers, and G. DiMego, 2002: Implementation of a new grid-scale cloud and precipitation scheme in the NCEP Eta Model. Proc. 15th Conf. on Numerical Weather Prediction, San Antonio, TX, Amer. Meteor. Soc., 280-283.

Fomin, B. A., and Yu. V. Gershanov, 1996: Tables of the benchmark calculations of atmospheric fluxes for the ICRCCM test cases, Part II: Short-wave results. Russian Research Center Kurchatov Institute, Rep. IAE- 5990/1, 42 pp.

Fouquart, Y., B. Bonnel, and V. Ramaswamy, 1991: Intercomparing shortwave radiation codes for climate studies. J. Geophys. Res., 96, 8955-8968.

Hinkelman, L. M., T. P. Ackerman, and R. T. Marchand, 1999: An evaluation of NCEP Eta Model predictions of surface energy budget and cloud properties by comparison with measured ARM data. J. Geophys. Res., 104, 19 535-19 549.

Hong, S.-Y., H.-M. Yuang, and Q. Zhao, 1998: Implementing of prognostic cloud scheme for a regional spectral model. Mon. Wea. Rev., 126, 2621-2639.

Huffman, G., R. F. Adler, M. M. Morrisey, D. T. Bovin, S. Curtis, R. Joyce, B. McGavock, and J. Susskind, 2001: Global precipitation at one-degree daily resolution from multisatellite observations. J. Hydrometeor., 2, 36-50.

Janjic, Z. I., 1994: The step-mountain eta coordinate model: Further development of the convection, viscous sublayer, and turbulence closure schemes. Mon. Wea. Rev., 122, 927-945.

Kanamitsu, M., W. Ebisuzaki, J. Woollen, S.-K. Yang, J. J. Hnilo, M. Fiorino, and G. L. Potter, 2002: NCEP-DOE AMIP-II Reanalysis (R-2). Bull. Amer. Meteor. Soc., 83, 1631-1643.

Lacis, A. A., and J. E. Hansen, 1974: A parameterization for the absorption of solar radiation in the earth's atmosphere. $J$. Atmos. Sci., 31, 118-133.

Marengo, J. A., M. W. Douglas, and P. L. Silva Dias, 2002: The South American low-level jet east of the Andes during the 1999 LBA-TRMM and LBA-WET AMC campaign. J. Geophys. Res., 107, 8079, doi:10.1029/2001JD001188.

_ W. R. Soares, C. Saulo, and M. Nicolini, 2004: Climatology of the low-level jet east of the Andes as derived from the NCEP-NCAR reanalyses: Characteristics and temporal variability. J. Climate, 17, 2261-2280.

Mellor, G. L., and T. Yamada, 1974: A hierarchy of turbulence closure models for boundary layers. J. Atmos. Sci., 31, 17911806.

Mesinger, F., Z. I. Janjic, S. Nickovic, D. Gavrilov, and D. G. Deaven, 1988: The stepmountain coordinate: Model description and performance for cases of Alpine lee cyclogenesis and for a case of Appalachian redevelopment. Mon. Wea. Rev., 116, 1493-1518.

Reynolds, R. W., N. A. Rayner, T. M. Smith, D. C. Stokes, and W. Wang, 2002: An improved in situ and satellite SST analysis for climate. J. Climate, 15, 1609-1625.

Rothman, L. S., and Coauthors, 1998: The HITRAN molecular database and HAWKS, 1996 edition. J. Quant. Spectrosc. Radiat. Transfer, 60, 665-710.

Saulo, A. C., M. Nicolini, and S. C. Chou, 2000: Model characterization of the South American low-level flow during the 1997-1998 spring-summer season. Climate Dyn., 16, 867-881.

Seluchi, M. E., and J. Marengo, 2000: Tropical-mid latitude exchange of air masses during summer and winter in South America: Climatic aspects and extreme events. Int. J. Climatol., 20, 1167-1190.

_, and S. C. Chou, 2001: Evaluation of two Eta Model versions for weather forecast over South America. Geofis. Int., 40, 219-237.

Slingo, J. M., 1987: The development of a cloud prediction model for the ECMWF model. Quart. J. Roy. Meteor. Soc., 113, 899-927.

Tarasova, T. A., and B. A. Fomin, 2000: Solar radiation absorption due to water vapor: Advanced broadband parameterizations. J. Appl. Meteor., 39, 1947-1951.

Vernekar, A. D., B. P. Kirtman, and M. J. Fennessy, 2003: Lowlevel jets and their effects on the South American summer climate as simulated by the NCEP Eta Model. J. Climate, 16, 297-311.

World Meteorological Organization, 1986: World Climate Research Programme: A preliminary cloudless standard atmosphere for radiation computation. WMO Tech. Doc. WCP112, WMO/TD 24, 53 pp.

Xu, K.-M., and D. A. Randall, 1996: A semiempirical cloudiness parameterization for use in climate models. J. Atmos. Sci., 53, 3084-3102.

Yamamoto, G., 1962: Direct absorption of solar radiation by atmospheric water vapor, carbon dioxide and molecular oxygen. J. Atmos. Sci., 19, 182-188.

Yang, G.-Y., and J. Slingo, 2001: The diurnal cycle in the Tropics. Mon. Wea. Rev., 129, 784-800.

Zhao, Q., and F. H. Carr, 1997: A prognostic cloud scheme for operational NWP models. Mon. Wea. Rev., 125, 1931-1953. 